\title{
An Evaluation of Formed Maintenance Programme Efficacy
}

\author{
Željko Đurić 1 - Ljubiša Josimović2 - Živoslav Adamović $^{3}$ - Ljiljana Radovanovićc ${ }^{3, *}$ - Goran Jovanov 4 \\ 1 Bauxite Corporation Milici, Bosnia and Herzegovina \\ 2 Polytechnical School Pozarevac, Serbia \\ 3 University of Novi Sad, Technical Faculty "Mihajlo Pupin" in Zrenjanin, Serbia \\ 4 International University of Brcko, Bosnia and Herzegovina
}

This paper presents the basic ideas for programming the maintenance of complex technical systems, which is a set of rules for determining the diagnostic mode of the constituent parts of the system in the actual exploitation process and decision making regarding the need for their replacement or on the extent of the necessary maintenance based on the information of the actual technical condition of the system.

Assuming that the condition based maintenance is, in fact, the management system of the technical state of the system in the exploitation process, upon choosing the strategy for the condition based maintenance we have performed an analysis of the applicability of formed variants of the maintenance programme and evaluated their efficiency by comparing them with basic indicators (for corrective and preventive maintenance). We have pointed out the importance of using the described maintenance programme to increase reliability level and decrease the stagnation of technical systems, which results in high efficiency, and thus increases the productivity of companies where the systems have been installed.

Keywords: reliability of technical systems, maintenance programme, technical diagnostics

\section{O INTRODUCTION}

The shortcomings in policies and strategies of preventive maintenance within large fields of practice have recently initiated a trend of the maintenance planning on the basis of the established condition of the system within the exploitation process (condition based maintenance) [1].

The main advantages of introducing the condition based maintenance lie mainly in the reduction of the maintenance costs (both direct and indirect) as well as in the decrease of the possibility of bringing to a production halt, although other positive effects can be produced, such as the following:

- providing the production of required amounts of proper quality goods,

- improving the safety of the working staff (operators and maintenance workers),

- decrease in dissipating both energy and raw materials necessary for the production and providing the operation of the constituent parts and/or the system within the regime of the highest level of use,

- better relationships with buyers of goods because of immediate deliveries as well as of the adequate quality of goods,

- greater satisfaction among the staff, particularly within the departments of production and maintenance etc.

The policy of preventive maintenance based on the realisation of planned activities at particular intervals, independently of the technical condition of the constituent parts and/or the system, does not provide sufficient operation and connection between the process of the alteration of the technical condition and the exploitation process [2].

A closer connection between them, by work planning and its periodical performance depending on the technical condition of the constituent parts and/ or the system obtained on the basis of diagnostics, is provided by maintenance strategies according to the condition.

Technical systems provide the possibility of applying a greater number of maintenance strategies according to the condition.

According to the standard EN 13306: 2001 (Maintenance Terminology) condition based maintenance is preventive maintenance based on performance and/or parameter monitoring and the subsequent actions [1].

The research [2] and [3] have contributed to these strategies being divided into two groups:

- maintenance according to condition with parameter control, and

- maintenance according to condition with reliability level control.

Maintenance according to condition with parameter control includes constant or periodic control and technical parameters measuring all the system's components and/or the system as a whole. The maintenance activities are performed when the values of the control parameters reach the usability level, or the pre-critical level.

The condition based maintenance with the control of the reliability level consists of collecting, processing and analysing the data on the reliability 
of the constituent parts and/or the system and of elaborating the decisions on the necessary planning activities of the maintenance concerning replacing or repairing the constituent parts of the system.

In the general analysis of recent documents [1] to [8] preventive maintenance processes, proactive maintenance, maintenance according to the condition, technical diagnostics and total maintenance are reviewed.

The authors specify the significance and the role of the maintenance according to the condition, while in documents [1], [2], [4] to [6], this kind of maintenance is defined as a form of preventive maintenance whose strategy of decision making on maintenance activities is based on periodic and constant technical control of the system in the exploitation process, and according to the results of the diagnostics control the decisions are made on the necessary deadline and the amount of planned maintenance activities.

Maintenance according to the condition is handled with the control of the parameters and the usage of the endoscopic method [7], so it can be concluded that the existing model of maintenance according to the condition reaches the goal of successful implementation of the diagnostic method in which planned maintenance activity duration is determined.

To some extent, the issue of the improvement of technical systems maintenance process arises, based on the implementation of different models of preventive maintenance, on the knowledge of a certain part of the system's condition, gained from the routine or constant observation [8].

In their paper Barros, et al. [4] present a new methodology for optimizing maintenance and monitoring performance. The performance of the monitoring device is modelled classically by receiver operating characteristic (ROC) curves. From a practical point of view, this approach leads to a very simple optimization scheme in which the optimal monitoring technology or structure can be chosen among a finite set of possible ones, on the basis of their impact on the maintenance performance and their own cost. At the same time, the maintenance parameters are optimally tuned to adapt to the current monitoring quality level.

Adjallah and Adzakpa [5] give important and useful results relating to the minimization of the sum of the flow time and the tardiness of tasks or jobs with unequal release dates (occurrence date), with application to maintenance planning and scheduling. First, the policy of real-time maintenance is defined for minimizing the cost of tardiness and critical states.
The required local optimality rule (flow time and tardiness rule) is proved, in order to minimize the sum or the linear combination of the tasks' flow time and tardiness costs. This rule has served to design a scheduling algorithm, with $\mathrm{O}\left(n^{3}\right)$ complexity when it is applied to schedule a set of $n$ tasks on one processor. To evaluate its performance, the results are compared with a lower bound that is provided in a numerical case study. Using this algorithm in combination with the tasks' urgency criterion, a real-time algorithm is developed to schedule the tasks on parallel processors. This latter algorithm is finally applied to schedule and assign preventive maintenance tasks to processors in the case of a distributed system. Its efficiency enables, as shown in the numerical example, the cost of preventive maintenance tasks expressed as the sum of the tasks' tardiness and flow time to be minimized. This corresponds to the costs of critical states and of tardiness of preventive maintenance.

In this paper we have made an attempt to point out the influence of formed variants of the maintenance programme on the increase of the reliability level of technical systems.

\section{FORMING THE MAINTENANCE PROGRAMME}

The maintenance programme will here refer to the set of accepted methods formed on the basis of documentary materials and the maintenance regime for the constituent parts and/or systems, which provide the given management of the technical condition as well as the reliability within the given condition of the exploitation process.

The maintenance programme of the constituent part and/or the system must be aimed at providing the highest level of efficacy of the constituent part and/or the system with optimal exploitation costs.

Forming the maintenance programme can be based on rational combining the condition based maintenance with traditional preventive maintenance.

Taking into account a great complexity of technical systems in the industry, this paper deals with forming the maintenance programme for the constituent parts of a section (e.g. the convertor section including the equipment), although this can be done for the constituent parts (fits) of the system as well.

The research into forming the maintenance programme for the constituent parts and/or the system should, in principle, contains three stages:

- forming the maintenance programme variants at the first level, 
- forming the maintenance variants at the second level,

- evaluating the efficacy and choice of the maintenance programme variant.

If the failure of the constituent part does not affect the reliability of the system in operation, then, when it comes to an increase of the intensity of the failure, it is the average costs for corrective and preventive replacement that are compared, and if those costs are the same, the constituent part of the system is maintained according to the condition by controlling the reliability level. If those corrective maintenance costs are greater than those of preventive maintenance, then the maintenance with the control of parameters is applied.

If the failure intensity is approximately constant, then the condition based maintenance with the control of the reliability level is applied.

If the failure of the constituent part of the system affects the reliability of the system in operation, it is the condition based maintenance that will be used with the increase of the failure intensity, whereas the condition based maintenance with the control of the reliability level will be applied with the non-increase intensity.

Evaluating the influence of the failure of the constituent part on the reliability of the system in operation is performed by comparing the probability of the occurrence of one of the possible conditions of the system with corresponding allowable values given by the equipment manufacturer, where the methods of mathematical statistics are used and the failure intensity is analysed. In order to form the diagram of the failure intensity it is necessary to process statistical data of the failures of the constituent parts of the system within the process of technical exploitation during a period of time that is no longer than 2 to 3 years. The analysis of constant proper functioning of the constituent parts can be performed according to the well-known order:

- forming the diagram of the failure intensity,

- according to the character of the alteration of the failure intensity, the assumption about the law on the distribution of the failure occurrence is made,

- checking the hypothesis on the law on the failure distribution according to Pearson etc.

According to the results of modelling the following can be determined:

- the frequency of entering particular conditions of the exploitation process,

- the average amount of the detected failures of the constituent parts and/or the system within particular conditions etc.
In this case, some indicators of the maintenance efficacy can also be calculated, such as the following:

- the probability of entering particular exploitation conditions,

- the efficiency coefficient of the constituent part and/or the system according to the purpose,

- $\quad$ specific stops due to maintenance,

- average time of the system renewal,

- specific maintenance costs of the constituent part and/or the system etc.

The influence of the characteristics of the constituent parts referring to the construction and exploitation on the efficacy of the application of different maintenance strategies and thus on the efficacy of the maintenance programme on the whole, should necessarily be analysed through the alterations of the reliability indicators and maintenance costs.

The annual economic effect of introducing the maintenance programme of the constituent parts and/ or the system can arise from:

- the reduction of the maintenance exploitation costs,

- the improvement of efficacy of the constituent parts and/or the system,

- the decrease of the amount of the spare parts to be replaced etc.

\section{SPARE PARTS SAVING BY INTRODUCING THE MAINTENANCE PROGRAMME}

The research conducted in steel industry shows that the probability of continuous operation of the constituent parts and/or the system, which are susceptible to accidental failures, can be described by the exponential and Weibull's distribution for the working period when the failure intensity is either constant or on the rise. For failures due to ageing (gradual failures) the probability of continuous operation can be described as normal, log-normal by Erlang's and Weibull's distribution during the working period when the failure intensity is on the rise.

On the basis of this research it is possible to make a maintenance programme for a technical system of a particular type or for more systems combined within working requirements, and thereby a plan of necessary spare parts replacements.

The use of the new maintenance programme, differing from the basic maintenance programme assumes a significant application of the maintenance strategies according to the condition, which results in the reduced use of the amount of spare parts. 
For the amount of the "saved" constituent parts of the $i$-type, which are maintained according to the condition with the control of parameters Eq. (1) [2].

$$
\Delta n_{i}=\eta_{A} T_{e f}\left(\frac{1}{t_{u r i}}-\frac{\eta_{i}}{m t_{u r 2}}\right) .
$$

It is possible to achieve the following economic effect:

$$
C_{R}^{1}=\eta_{i} T_{e f} \sum_{i=1}^{r_{d}}\left(\frac{1}{t_{u r 1}}-\frac{\eta_{i}}{m t_{u r 2}}\right) n_{i} C_{r / d},
$$

where:

$\eta_{A}$ is the efficiency coefficient of the constituent part of the system before introducing the maintenance programme (with the basic maintenance programme),

$\eta_{B}$ is the efficiency coefficient of the constituent part after introducing the maintenance programme,

$T_{e f}$ is the annual number of hours $\left(T_{e f}=8760 \mathrm{~h}\right)$,

$r_{d}$ is the amount of the constituent parts of the system which are maintained according to the condition with the control of parameters,

$t_{u r 1}$ is the average time during the work between two failures for the $i$-type constituent part [h],

$m$ is the coefficient of the decrease of the output of the $i$-type constituent part of the system when its parameter reaches the wear out limit,

$t_{u r 2}$ is the average time while working with the condition based maintenance $[\mathrm{h}]$,

$\eta_{i}$ is the ratio of the efficiency coefficients of the constituent part of the system before and after introducing the maintenance programme $\left(\eta_{i}=\eta_{B}\right.$ $\left./ \eta_{A}\right)$,

$n_{i} \quad$ is the amount of the spare parts of the $i$-type within one system,

$C_{r / d}$ is the price of one spare part of the $i$-type.

The annual economic effect Eq. (3) is produced for the constituent parts of the system which are maintained according to the condition with the control of the reliability level:

$$
C_{R}^{2}=\eta_{A} \sum_{i=1}^{n_{P}}\left(\frac{1}{t_{u r 1}}-\frac{\eta_{i}}{t_{u r 2}}\right) n_{i} C_{r / d},
$$

where:

$n_{p}$ is the amount of spare parts which are maintained according to the condition with the control of the reliability level.

Expressing the average time during work $\left(t_{u r 1}\right)$ with the parameters of the exponential, normal, lognormal, Erlang's and Weibull's laws and classifying them into Eqs. (2) and (3), the total saving of spare parts is achieved by introducing the maintenance programme Eq. (4) [3]:

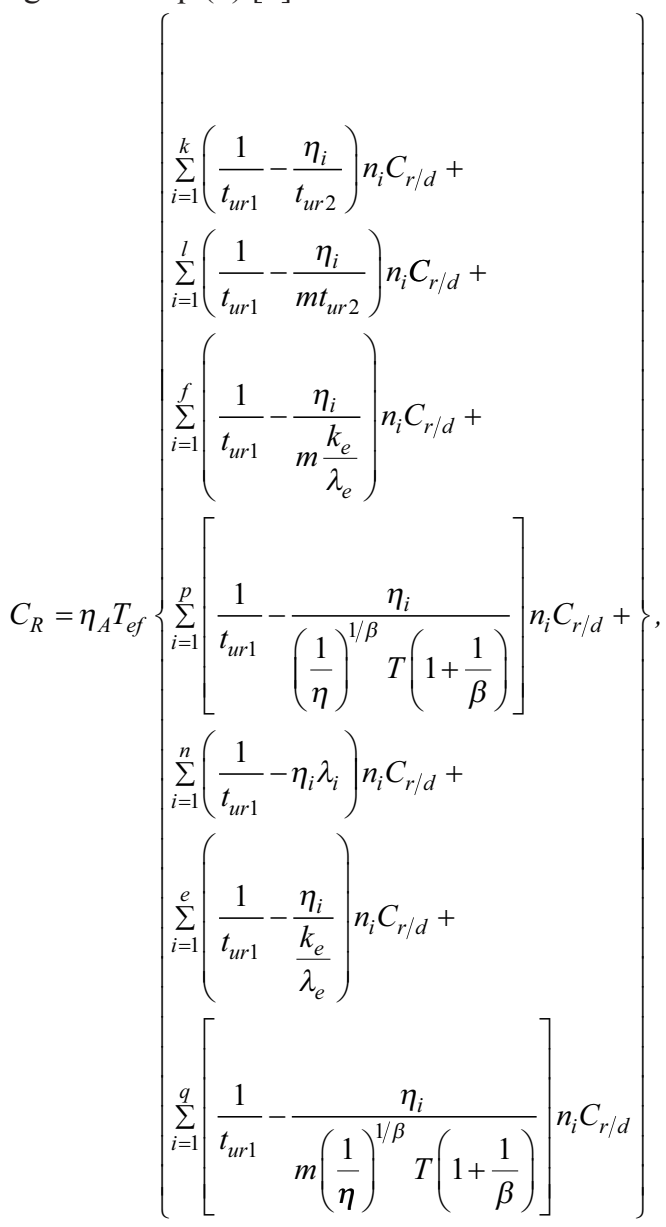

where:

$k, l$ is the amount of the spare parts which are maintained according to the condition with the control of the reliability level and control of the parameters and which have the normal and log- normal distribution of the probability of continuous work,

$n$ is the amount of the spare parts which are maintained according to the condition with the control of the reliability level and which have the exponential distribution of the continuous work with the parameter $\lambda_{i}$,

$e, f$ is the amount of the spare parts which are maintained according to the condition with the control of the reliability level and the control of parameters, which have Erlang's distribution of the probability of continuous work with the parameters $k_{e}$ and $\lambda_{e}$,

$p, q$ is the amount of the spare parts which are maintained according to the condition with the 
control of the reliability level and the control of parameters, which have Weibull's distribution of the probability of continuous work with the parameters $\beta$ and $\eta$,

$t_{u r 2}$ is the mathematical expectation of the average time during work for normal and log-normal distribution,

$r$ is gamma function.

In mathematical modeling, when preparing a maintenance strategy, equipment utilization rate and the cost of lost production per tim. should be considered.

The utilization rate must be considered when equipment is designed under competitive conditions. This rate consists of the following factors: the quality of equipment and its operation and the operational (demand) situation. As a utilization criterion we took the utilization function $F$, which should be optimized over the planned time $T$ to produce $N$ part, Eq. (5):

$$
F=\frac{P-C}{T},
$$

where $P$ is the sale price of $N$ parts, and $C$ is the cost of the parts [9].

The paper [10] explains and justifies the necessity and the importance of using the shift level of the utilization of capacity as the stochastic variable in determining the total level of the capacity utilization in the production process by using the method of work sampling. The conclusion is that the shift level of capacity utilization as the stochastic variable in work sampling is the model that solves the problem of determining the total level of capacity utilization in a convenient way with accurate results.

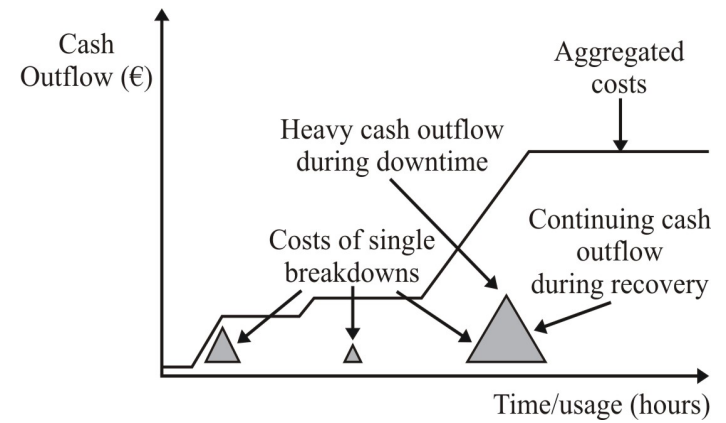

Fig. 1. Typical cash flow diagram illustrating the cost of lost production

The cost of lost production is a random set of peaks in the cash flow diagram as shown in Fig. 1. If treated independently, this cost can appear as a minor problem, but if aggregated, the result can be quite startling. Even if it is possible to calculate the cost of lost production accurately, the frequency and duration of future break-downs should still be estimated before making a cash flow statement. Accordingly, it is important to have good past records if we are to do any better than just guess a value. If breakdowns are purely random occurrences, then past records are not going to be enough to predict precise savings that could be included in a sound financial case. They may give an indication of the likely cost when a breakdown happens [11].

This is a model for calculating the cost of lost production during maintenance actions in Eq. (6):

$$
C_{L P}=N_{W P} \times R C,
$$

where $C_{L P}$ is the cost of lost production, $N_{W P}$ the number of days without production, and $R C$ the replacement cost.

A model for determining the distribution of the net present value (NPV) characterizing the production systems is developed in the paper [12]. The model has significant advantages compared to models based on the expected value of the losses from failures. The model developed in this study reveals the variation of the NPV due to the variation of the number of critical failures and their times of occurrence during the entire useful life-cycle of the systems.

At the heart of the NPV-model there is a model for tracking the losses from failures $L_{i}$. These have three major components:

- cost of lost production $C_{L P}$,

- cost of intervention $C_{I}$ to initiate repair which also includes the cost of mobilization of resources for repair, and

- cost of replaced components and cost of repair $C_{R}$.

As a result, the losses from failures $L$ can be presented as a sum of these three components, Eq. (7). The losses from failures $L_{i}=C_{L P, i}+C_{I, i}+C_{R, i}$ in the $i$-th year are a sum of the cost of lost production $C_{L P, i}$, the cost of intervention $C_{I, i}$ and the cost of repair/ replacement $C_{R, i}$ in the $i^{\text {th }}$ year.

$$
L_{i}=C_{L P, i}+C_{I, i}+C_{R, I} .
$$

The cost of lost production $C_{L P}$ is calculated from Eq. (8):

$$
C_{L P}=L_{d} \times V_{d} \times P_{V},
$$

where $L_{d}$ is the number of lost production unit-days, $V_{d}$ is the volume of production per day per production unit and $P_{V}$ is the selling price per unit volume production. 


\section{FORMING THE MAINTENANCE PROGRAMME FOR THE ENGINE-ROOM OF CONVERTORS}

The engine-room of convertors (Fig. 2) consists of: a firth crane, a charging crane, a magnetic crane, the preparation of non-metal additives, conveyors $\mathrm{T} 1$ and $\mathrm{T} 2$, the engine-room of blowers, the installation for water and oxygen, the delivery of non-metal additives, a scrubber, an exhaust fan and a convertor.

The reliability of the engine-room of convertors $\left(R_{u k}\right)$ can be calculated as in Eq. (9) (the signs are from Fig. 2):

$$
\begin{gathered}
R_{u k}=R_{1}^{\prime}\left[1-\left(\left(1-R_{3}^{\prime}\right) R_{K_{1}}\right)\left(\left(1-R_{4}^{\prime}\right) R_{K_{2}}\right)\right], \\
R_{1}^{\prime}=R_{u k}\left[1-\left(1-R_{s k}\right)\left(1-K_{S K}\right)\right] . \\
\cdot\left[1-\left(1-R_{M K}\right)\left(1-K_{M K}\right)\right] . \\
\cdot\left[1-\left(1-R_{N} R_{T 1} R_{T 2}\right)\left(1-K_{T}\right)\right], \\
R_{3}^{\prime}=R_{D 1} R_{i 1} R_{N D 1} R_{S 1} R_{V 1}, \\
R_{4}^{\prime}=R_{D 2} R_{i 2} R_{N D 2} R_{S 2} R_{V 2}
\end{gathered}
$$

where:

$R_{u k}$ is the reliability of firth crane,

$R_{K 1}$ is the reliability of convertor 1 ,

$R_{K 2}$ is the reliability of convertor 2 ,

$R_{s k}$ is the reliability of charging crane,
$R_{M K}$ is the reliability of magnetic crane,

$R_{N}$ is the reliability of engine room of non-metal additives,

$R_{T 1}$ is the reliability of conveyor $\mathrm{T} 1$,

$R_{T 2}$ is the reliability of conveyor $\mathrm{T} 2$,

$R_{D 1}, R_{D 2}$ are the reliability of engine-rooms of blowers,

$R_{i 1}, R_{i 2}$ are the reliability of water and oxygen armature,

$R_{N D 1}, R_{N D 2}$ are the reliability of delivery of non-metal additives,

$R_{S 1}, R_{S 2}$ are the reliability of scrubber,

$R_{V 1}, R_{V 2}$ are the reliability of exhaust fan,

$K_{S K}, K_{M K}, K_{T}$ are coefficients.

The coefficients $K_{S K}, K_{M K}, K_{T}$ are a measure of aggravation of total productivity on condition that a failure occurs on the branch (i) (if they equal 0 , the system does not function on the whole).

The analysis of constant proper functioning of the constituent parts (subsystems) of the engine-room of convertors (systems) can be performed on the basis of the statistical data obtained during the time of exploitation. The aim of processing the statistical data is to adopt a law on work distribution until the failure of all the subsystems. By breaking the above

\begin{tabular}{|c|c|c|c|c|}
\hline $\begin{array}{l}\text { Position of } \\
\text { const. part }\end{array}$ & $\begin{array}{c}\text { Name of const. part } \\
\text { of the engine-room of convertors }\end{array}$ & $\begin{array}{l}\text { Law on distribution of continuous work } \\
\text { and its parameters }\end{array}$ & $\begin{array}{l}\text { Character of alteration } \\
\text { of failure intensity }\end{array}$ & $\begin{array}{l}\text { Proposed application of } \\
\text { maintenance strategy }\end{array}$ \\
\hline 1 & Firth crane & exponential $\lambda=204 \cdot 10^{-6}$ & $\approx$ const & CBM-CRL \\
\hline 2 & Charging crane & Weibull $R=e^{-(t / 6294)^{1.95}}$ & increases & CBM-CP \\
\hline 3 & Magnetic crane & Weibull $R=e^{-(t / 5893)^{1.68}}$ & $\approx$ const & CBM-CRL; CBM-CP \\
\hline 4 & Engine-room of non-metal additives & Erlang 2nd progression $\lambda=2.22 \cdot 10^{-6}$ & increases & CBM-CRL \\
\hline 5 & Conveyor, $T_{1}$ & normal $m=9864, \delta=3869$ & increases & PM \\
\hline 6 & Conveyor, $T_{2}$ & normal $m=8434, \delta=3904$ & increases & PM \\
\hline 7 & Engine-room of blowers & exponential $\lambda=1.86 \cdot 10^{-6}$ & $\approx$ const & CBM-CRL \\
\hline 8 & Water\&oxygen armature & Erlang 2nd progression $\lambda=4.15 \cdot 10^{-6}$ & increases & CBM-CP \\
\hline 9 & Delivery of non-metal additives & normal $m=7647, \delta=4098$ & increases & PM \\
\hline 10 & Scrubber & normal $m=8868, \delta=3338$ & increases & CBM-CRL \\
\hline 11 & Exhaust fan & Weibull $R=e^{-(t / 4682)^{1.85}}$ & increases & CBM-CP \\
\hline 12 & Convertor & Weibull $R=e^{-(t / 4468)^{2.2}}$ & increases & СВM-СР \\
\hline \multicolumn{5}{|c|}{$\begin{array}{l}\text { PM - preventive maintenance according to "constant durability" } \\
\text { CBM-CP - condition based maintenance with the control of parameters } \\
\text { CBM-CRL - condition based maintenance with the control of the reliability level }\end{array}$} \\
\hline
\end{tabular}
mentioned subsystems into their constituent parts, it is also possible to make a proper functioning analysis of all the constituent parts of the subsystems.

Table 1. The results of the analysis of constant proper functioning and the proposed variants of the maintenance for the constituent parts of the engine-room of convertors 
(i)

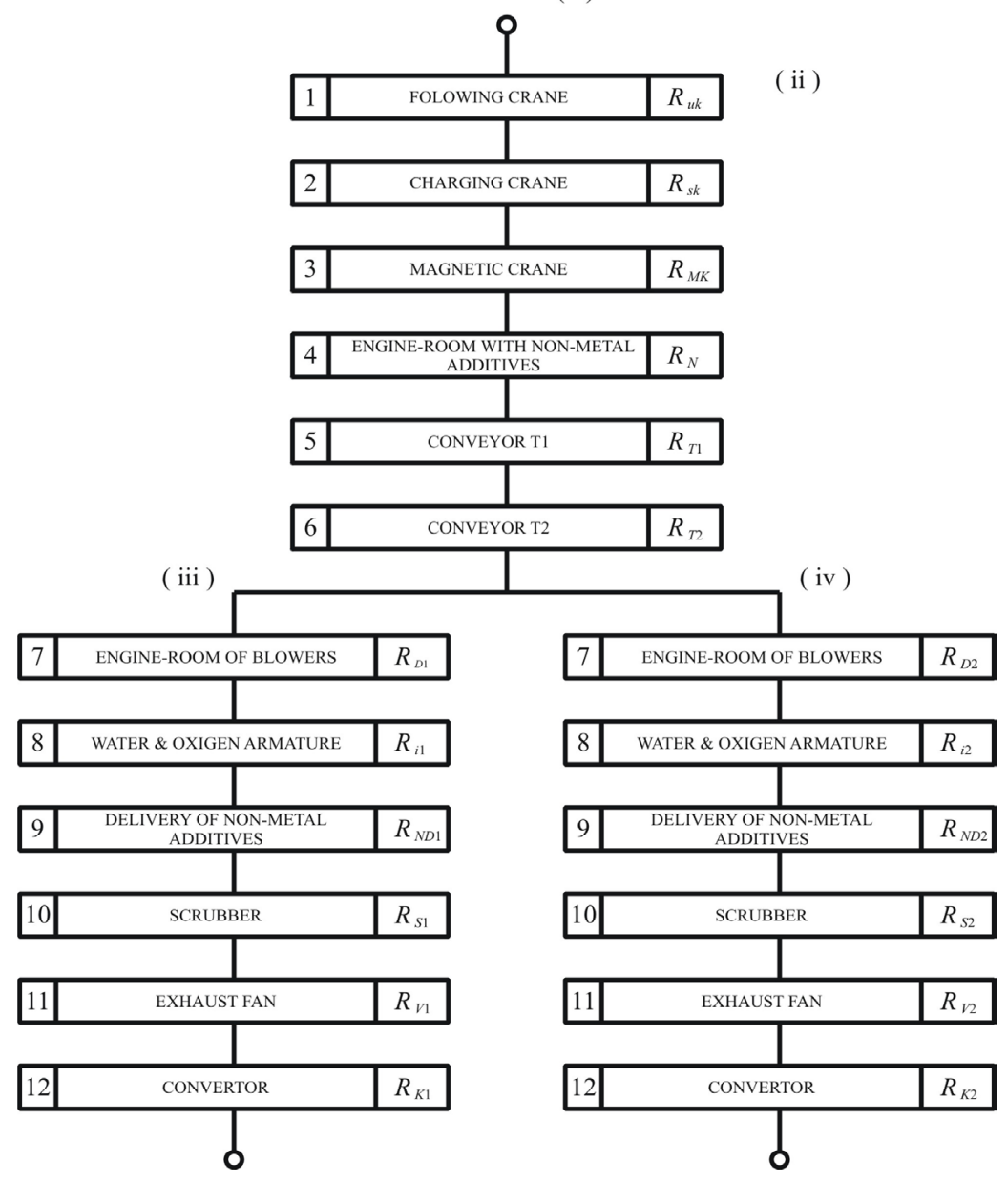

Fig. 2. Schema of the engine-room of convertors

The confirmed hypotheses on the congruence of the statistical distributions with the theoretical ones enable determining the distribution parameters of constant proper functioning, primarily drawing conclusions on the character of the alteration of the failure intensity.

When forming the variants of the maintenance programme for the engine-room of convertors, the initial point is that the costs of corrective and preventive maintenance (both direct and indirect) are always greater than those of the preventive maintenance.

The results of the analysis of the constant proper functioning of the constituent parts of the engineroom of convertors, as well as the suggested variant of maintenance are given in Table 1.

It can easily be seen in Table 1 that for 9 out of 12 considered constituent parts of the engine-room of convertors the application of the condition based maintenance is suggested.
The performed analysis and the choice of the maintenance strategy for each constituent part separately enable forming the maintenance programme (standard).

The evaluation of the efficacy of the formed programme variants has been made by comparing them with the basic efficacy indicators (for corrective and preventive maintenance), whereby the following results have been obtained:

- the operative readiness of the engine-room of convertors has increased by 6.9 to $8.1 \%$,

- the reliability of the engine-room of convertors has increased by 4 to $8.5 \%$,

- $\quad$ specific maintenance costs (direct and indirect) have decreased by 14 to $21 \%$,

- the annual economic effect of the application of the maintenance programme according to the condition is (18 to 22$) \cdot 10^{6} €$. 
These results also refer to developed maintenance programmes for the constituent parts of some subsystems of the engine-room of convertors.

The influence of the number of the formed variants of the maintenance programme ( $\%$ of the included constituent parts of the system) on the reliability of the engine-room of convertors is shown in Fig. 3, whereby a field of a relative alteration of the reliability which has been reached at the current level of the chosen maintenance programmes $(40 \%$ of all the included technical systems within the engine-room of convertors) can be noticed. The alteration of the readiness of the engine-room of convertors in relation to the time at work is shown in Fig. 4.

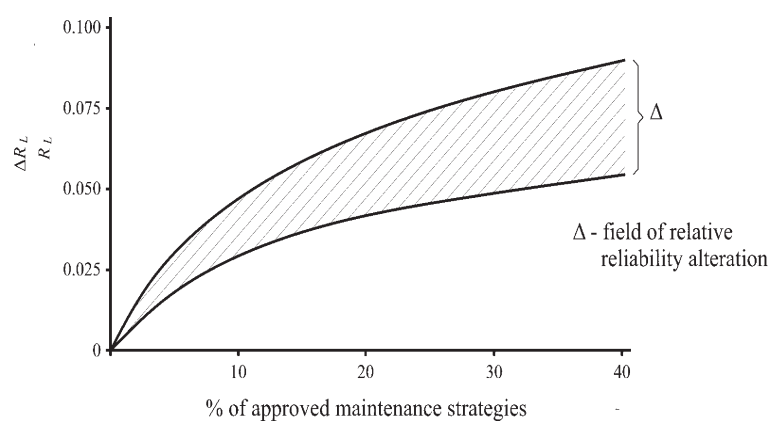

Fig. 3. The influence \% of forming the variants of the maintenance programme on the reliability of the engine-room of convertors

In Fig. $3 R_{N}$ is System reliability (of engine-room of convertors) after choice of maintenance program, $R_{L}$ Basis reliability (before choice of maintenance program), and $\Delta R_{L}=R_{N}-R_{L}$.

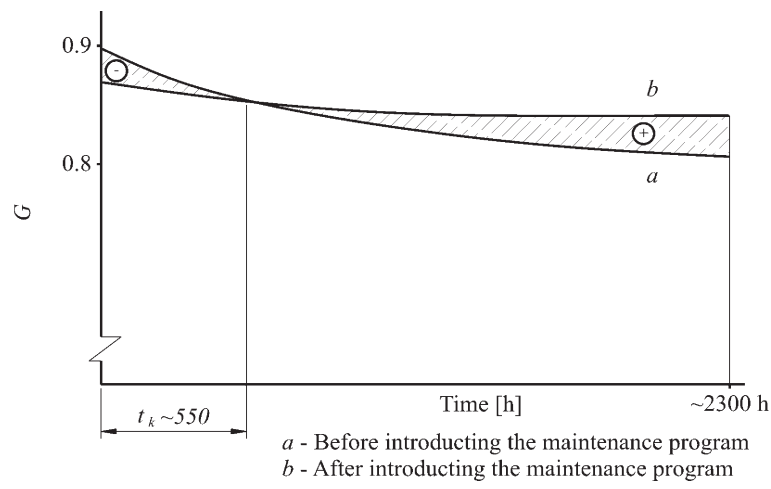

Fig. 4. The alteration of readiness of the engine-room of convertors

The occurrence of the period $t_{k}$ (Fig. 4) can be explained by the following fact: in the past the replacement of spare parts used to be performed without a sufficient use of reserves of usability and the parts were mainly imported. Nowadays, domestic spare parts are used and their basis (projected) reliability is a little lower than that of the imported parts.

By introducing the maintenance programme for the engine-room of convertors the specific costs of spare parts and materials have been reduced (Fig. 5).

Some benefits obtained by introducing the maintenance programme are shown in Fig. 6.

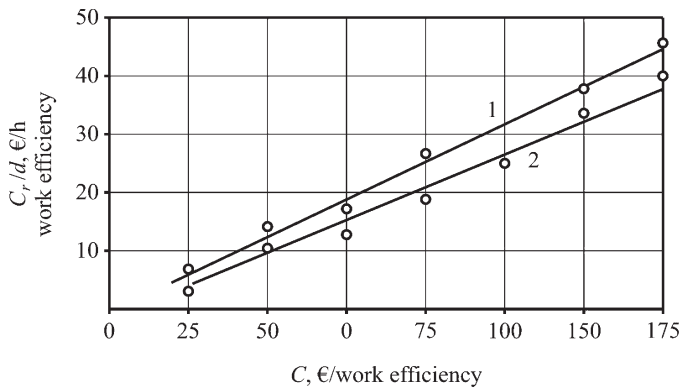

1 - Program of preventive maintenance

2 - Program of maintenance according to

$C$ - Specific spare parts costs condition

Fig. 5. Specific costs of spare parts and materials depending on specific costs of maintaining the engine-room of convertors

\section{CONCLUSION}

Condition monitoring prevents failure modes from occurring by detecting and avoiding failures. Thus, a measured trend of increasing temperature and vibrations in a bearing indicates intensive wear out and incipient failure, which can be prevented by a timely replacement of the worn-out bearing. Condition monitoring of operating components and systems also provides an early problem diagnosis which helps to plan and organise the repair in advance. By reducing the mobilization time and the downtime for repair, condition monitoring reduces the financial losses associated with failure. Controlling all processing parameters in safe ranges is another example of a dual measure reducing both the likelihood of failures and the consequences of failure.

By introducing the maintenance programme it is possible to: improve the efficacy of engine rooms of convertors, reduce the total maintenance costs, improve the organisation of production and maintenance, reduce the consumption of electric power, reduce the number of complaints about products, improve the level of co-operation with partners, improve the level of motivation for work and improve the level of planned activities concerning maintenance etc.

The results obtained upon implementation of the maintenance programme, as well as some other results not presented in this paper, indicate good congruence with the hypothesis of the significance of the above 
described maintenance programme for the increase of the reliability level and its contribution to the reducing the stagnation and high level of utilizing technical systems and company productivity.

a)

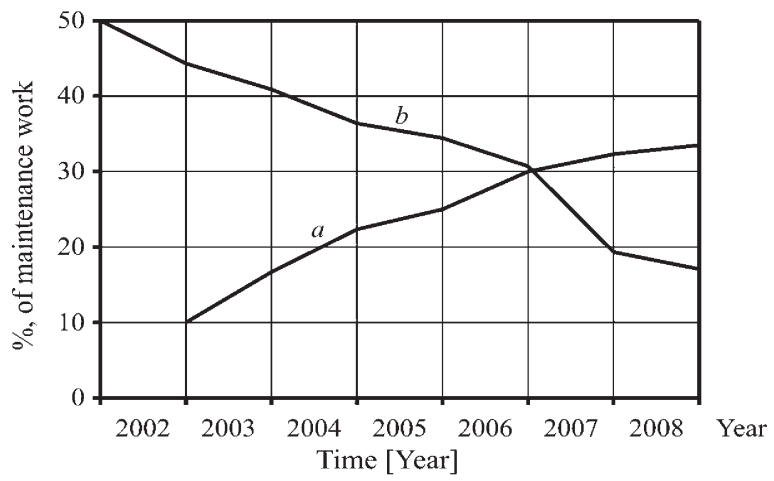

$a$ - planned works;

$b$ - unplanned works;

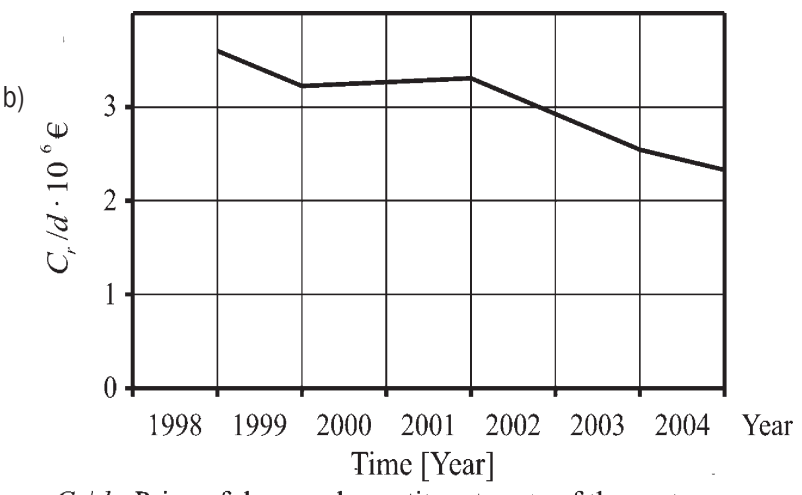

$C_{r} / d$ - Price of damaged constituent parts of the system

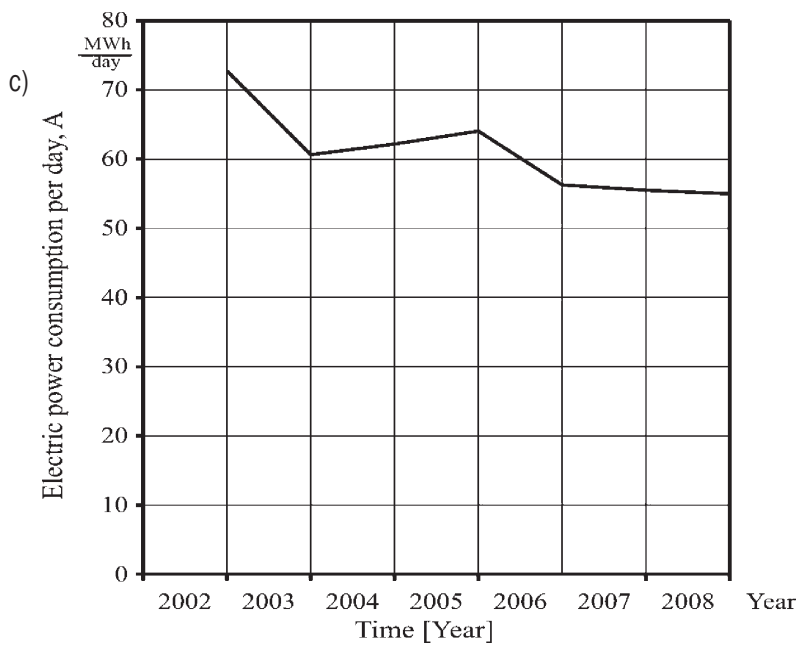

Fig. 6. Benefits obtained by introducing the maintenance programme in the sections of steelworks; a) maintenance work,

b) price of damaged constituent parts of the system, c) electric power consumption per day

\section{ACKNOWLEDGMENTS}

This paper is the result of the research within the project TR 34028, financially supported by the Ministry of Science and Technology of Serbia.

\section{REFERENCES}

[1] Standard EN 13306, Maintenance terminology (2001). CEN, European Committee for Standardization, Brussels.

[2] Adamovic, Z., Adamovic, M., (2008). Technical Diagnostics. Technical faculty Mihajlo Pupin Zrenjanin. (in Serbian)

[3] Adamovic, Z. (1998). Technology of Maintenance. University of Novi Sad, Novi Sad. (in Serbian)

[4] Barros, A., Grall, A., Berenguer, C. (2007). Joint modelling and optimization of monitoring and maintenance performance for a two-unit parallel system. Proceedings of the Institution of Mechanical Engineers, Part O: Journal of Risk and Reliability, vol. 221, no. 1, p. 1-11, DOI:10.1243/1748006XJRR31.

[5] Adjallah, K.H., Adzakpa, K.P. (2007). Minimizing maintenance cost involving flow-time and tardiness penalty with unequal release dates. Proceedings of the Institution of Mechanical Engineers, Part O: Journal of Risk and Reliability, vol. 221, no. 1, p. 57-65, DOI:10.1243/1748006XJRR24.

[6] Puharić, M., Ristić, S., Kutin, M., Adamović, Ž. (2007). Laser doppler anemometry in hydradynamyc testing. Journal of Russian Laser Research, vol. 28, no. 6, p. 619-628, DOI:10.1007/s10946-007-0047-y.

[7] Bulatović, M., Šušić, J. (2007). Condition Maintenance - Applying an Endoscopic Method. Strojniški vestnik Journal of Mechanical Engineering, vol. 53, no. 5, p. 329-347.

[8] Semolič, B., Jovanović, P., Kovačev, S., Obradović, V. (2008). Improving Repair Management of Bucket Wheel Excavator SRs1200 by Application of Project Management Concept. Strojniški vestnik - Journal of Mechanical Engineering, vol. 54, no. 6, p. 398-412.

[9] Nikiforov, D., Kutukov, A.A. (1994). Method to determine the utilization rate of equipment in the petroleum and chemical industry. Chemical and Petroleum Engineering, vol. 30, no. 3, p. 109-111, DOI:10.1007/BF01147882.

[10] Klarin, M.M., Cvijanovic, J.M., Spasojevic Brkic, V.K. (2000). The shift level of the utilization of capacity as the stochastic variable in work sampling. International Journal of Production Research, vol. 38, no. 12, p. 2643-2651, DOI:10.1080/002075400411402.

[11] Mobley, K.R. (2002). An Introduction to Predictive Maintenance. Plant Engineering, Amsterdam.

[12] Todinov, M.T. (2006) Reliability value analysis of complex production systems based on the losses from failures. International Journal of Quality \& Reliability Management, vol. 23, no. 6, p. 696-718, DOI:10.1108/02656710610672498. 